\title{
Verification of 1D numerical model for heat conduction in human tissue by means of thermography
}

\author{
by I. Boras, M. Suša and S. Švaić
}

Faculty of mechanical engineering and naval architecture, Zagreb, Croatia

\begin{abstract}
The paper presents the results of simulation of the heat transport in the human tissue by means of $1 \mathrm{D}$ numerical model and experimentally obtained data. The model is based on the control volume numerical method with the skin temperature and heat losses to the surrounding as the boundary conditions. The thermodynamical properties of the tissue were taken from the relevant literature. The results obtained by simulation are compared with the data given in lit. [1]. The temperature droop in upper arm tissue of the observed subject is presented graphically, while the temperature distribution on the upper arm surface is given by thermograms.
\end{abstract}

\section{Introduction}

The thermal comfort of human being is defined with many parameters such as: air temperature and humidity, air velocity and quality, temperatures of the surrounding objects and physical activity. The reaction of the human body to particular situation can be divided in two categories, active and passive. Conscious active reactions are dressing and undressing and unconscious are sweating and shivering. Passive reactions of human body depend on the heat transfer with the surrounding. In the case of thermal unbalance between the body and surrounding the body temperature can increase or decrease. Both situations can be dangerous. The zone of thermal comfort for sedentary humans where mean radiant temperature equals dry bulb temperature and clothing thermal conductance is $10,8 \mathrm{~W} /\left(\mathrm{m}^{2} \mathrm{~K}\right)$ is given on fig. 1. The goal of the research was development of the numerical model by means of which the temperature distribution in the human tissue could be calculated. The boundary conditions for the model are data obtained by thermographic measurements.

\section{Thermal balance}

The thermoregulatory system of human body is maintaining its temperature constant. The energy supplied to the body by food transforms in heat and mechanical work. The metabolic rate is a total energy realised by oxidation in human body per unit time. The heat dissipation from human body to the surrounding takes place through heat and mass transfer.

A balance of a human body is given by Eq. (1)

$$
M-W-Q_{m}-Q_{h}=0
$$




$$
\frac{M}{A} \cdot(1-\eta)-q_{m}-q_{h}=0
$$

where: $\quad A=1,77 \mathrm{~m}^{2}$, average surface area of human body,

$\eta$ - efficiency of human activity,

$Q_{m}$ - heat flow rate due to mass exchange,

$Q_{h}$ - heat flow rate due to heat transfer,

$W$ - total physical work rate (power).

\section{Experiment}

The experimental part of the work was done on the subject at rest in the conditioned room. The period of accommodation on the certain air temperature and humidity was at least one hour. The thermograms of the subject upper arm were taken from the distance of $1 \mathrm{~m}$ with IR camera FLIR ThermaCAM SC2000 at the ambient temperatures of: $18,22,25,28{ }^{\circ} \mathrm{C}$ and relative humidity of $20 \%$. The results of thermographic measurements are presented in Table 1 . They were obtained from the thermograms by means of ThermaCAM Researcher 2002 software. The thermograms for one set temperature are presented on fig. 2. The emissivity of the human skin was taken as $\varepsilon=0,97$ according to lit. [1].

\section{Numerical model}

The numerical model is based on the control volume method and is expressed in cylindrical coordinates. The upper arm was assumed to be a cylinder having outer diameter of $100 \mathrm{~mm}$. The model has four layers with outer radius: core $28 \mathrm{~mm}$, muscle $44 \mathrm{~mm}$, fat $48 \mathrm{~mm}$ and skin $50 \mathrm{~mm}$. The thermal conductivity was taken according to lit. [1] as: $\lambda=0,418 \mathrm{~W} / \mathrm{mK}$ for core and muscle, and $\lambda=0,334 \mathrm{~W} / \mathrm{mK}$ for fat and skin. The 1D stationary heat conduction numerical model has 18 control volumes having thickness of $\Delta r=2 \mathrm{~mm}$. The source term of equal intensity is added to each control volume of single layer. It reperesents a heat transported by blood and metabolic rate. The observed segment is shown on fig. 3 and control volume net on fig. 4.

\subsection{Boundary conditions}

Set point temperature of core $t_{\mathrm{c}}=35,53^{\circ} \mathrm{C}$ at $r=14 \mathrm{~mm}$

Heat transfer coefficients

Radiant: $\quad h_{\mathrm{r}}=4,2 \mathrm{~W} / \mathrm{m}^{2} \mathrm{~K}$

Convective: $h_{\mathrm{h}}=2,1 \mathrm{~W} / \mathrm{m}^{2} \mathrm{~K}$

Basal evaporation loss $q_{\mathrm{e}}=5,52 \mathrm{~W} / \mathrm{m}^{2}$

Basal heat production ratio related to the core heat production

$n_{\mathrm{c}}=1$

$n_{\mathrm{m}}=0,8988$

$n_{\mathrm{f}}=0,5941$

$n_{\mathrm{s}}=0,8534$ 
Skin temperature $t_{\mathrm{s}}$ is obtained from thermograms.

Heat losses from the surface

$$
\begin{aligned}
& Q_{r}=h_{r} \cdot A_{s} \cdot\left(t_{s}-t_{a}\right) \\
& Q_{r}=h_{h} \cdot A_{s} \cdot\left(t_{s}-t_{a}\right) \\
& Q_{e}=q_{e} \cdot A_{s}
\end{aligned}
$$

\subsection{Heat balance}

In stationary state the heat losses from the observed surface segment are equal to the total heat production in the segment volume

$$
Q_{r}+Q_{h}+Q_{e}=Q_{c}+Q_{m}+Q_{f}+Q_{s}
$$

where the indexes refer to:

\begin{tabular}{|c|c|c|c|c|c|}
\hline \multicolumn{2}{|c|}{ Measurement No } & 1 & 2 & 3 & 4 \\
\hline \multicolumn{2}{|c|}{$t_{\mathrm{a}},{ }^{\circ} \mathrm{C}$ measured } & 28 & 25 & 22 & 18 \\
\hline \multicolumn{2}{|c|}{$t_{\mathrm{s}},{ }^{\circ} \mathrm{C}$ measured } & 33,47 & 30,3 & 28,47 & 26,77 \\
\hline \multirow{4}{*}{$\begin{array}{l}\text { Heat sources } \\
\qquad \mathrm{W} / \mathrm{m}^{3}\end{array}$} & $q_{\mathrm{c}}$ & 1740,4 & 1743,4 & 2145,8 & 2745,1 \\
\hline & $q_{\mathrm{m}}$ & 1566,1 & 1566,9 & 1928,7 & 2467,3 \\
\hline & $q_{\mathrm{f}}$ & 1029,3 & 1035,7 & 1274,8 & 1630,9 \\
\hline & $q_{\mathrm{s}}$ & 1485,8 & 1487,8 & 1831,3 & 2342,7 \\
\hline \multicolumn{2}{|c|}{ Heat production, $\mathrm{W}$} & 1,035 & 1,029 & 1,243 & 1,590 \\
\hline \multicolumn{2}{|c|}{$\begin{array}{l}\Delta t,{ }^{\circ} \mathrm{C} \\
\text { tissue temperature droop }\end{array}$} & 2,28 & 2,79 & 3,4 & 4,29 \\
\hline \multicolumn{2}{|c|}{$\begin{array}{l}\text { Surface heat flux } \\
q, \mathrm{~W} / \mathrm{m}^{2}\end{array}$} & 38,37 & 39,3 & 47,45 & 60,7 \\
\hline \multicolumn{2}{|c|}{$t_{\mathrm{c}},{ }^{\circ} \mathrm{C}$ calculated } & 35,75 & 33,09 & 31,87 & 31,06 \\
\hline
\end{tabular}

$$
\begin{array}{lll}
c & - & \text { core } \\
\mathrm{m} & - & \text { muscle } \\
\mathrm{f} & - & \text { fat } \\
\mathrm{s} & - & \text { skin } \\
\mathrm{a} & - & \text { ambient }
\end{array}
$$

\section{Results of the numerical analysis}

Table 1. The results of numerical analysis

The temperature distributions in the observed segment are given on fig. 5 . 


\section{Conclusion}

The obtained results show that, at the ambient temperature of $28{ }^{\circ} \mathrm{C}$, the core temperature is nearly the same as given in referent lit. [1]. For the three other ambient temperatures the core must be at lower temperature when the observed segment of upper arm is in thermal balance with the surrounding and the heat conduction coefficients remain unchanged. The obtained metabolic rate of heat production and the heat exchanged by blood flow were higher than those given in lit. [1], [6]. The specific heat flow from the skin surface increases at lower ambient temperatures and is within the values given in reference literature.

\section{REFERENCES}

[1] Arthur T. Johnson, Biomechanics and exercise physiology, John Wiley \& Sons, Inc., New York(1991)

[2] Cornwell K., The Flow of Heat, Van Nostrand Reinhold Company, London, (1977)

[3] Ferreira,M.S., Yanagihara, J.I., Development of the passive system of a human thermal model, BED-Vol. 50, 2001 Bioengineering Conference ASME (2001)

[4] Kastberger G, Stachl R., Infrared imaging technology and biological applications.Behav Res Methods Instrum Comput. Aug. 35(3):429-39, (2003)

[5] Ellis W, Cheng S., Intraoperative thermographic monitoring during neurogenic thoracic outlet decompressive surgery. Vasc Endovascular Surg. Jul-Aug., 37(4):253-7, (2003)

[6] Peterson F., Climate Calculations, Department of Heating and Ventilation, Royal Institute of Technology, Stockholm (1999)

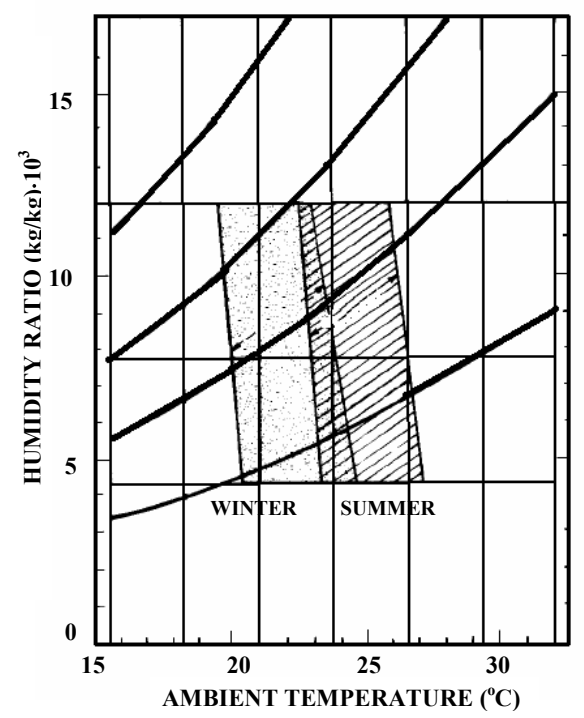

Fig. 1 The comfort zone for sedentary humans 
http://dx.doi.org/10.21611/qirt.2004.031
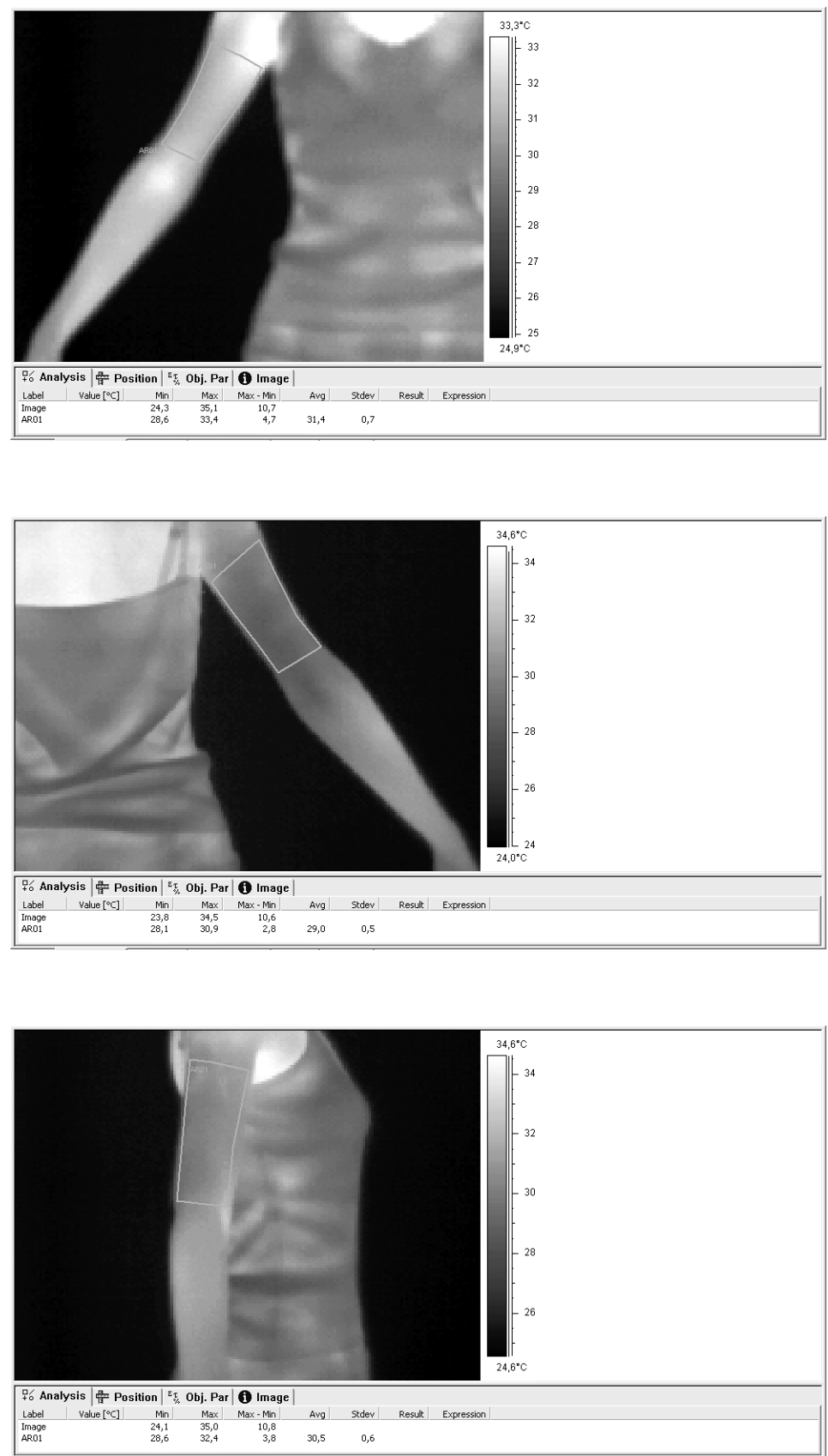

Fig. 2 The thermograms 


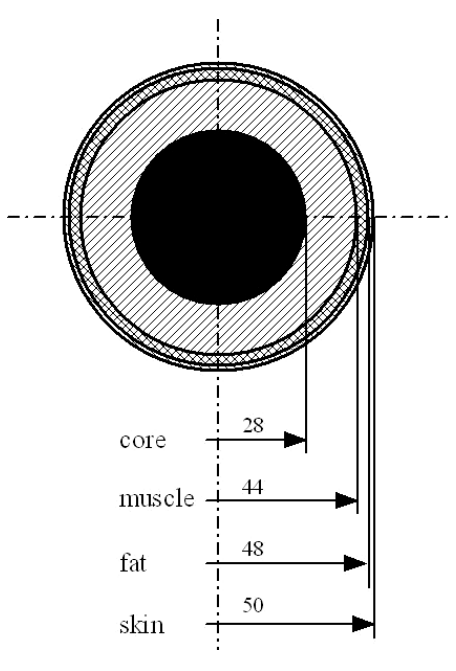

Fig. 3 The cross section of upper arm

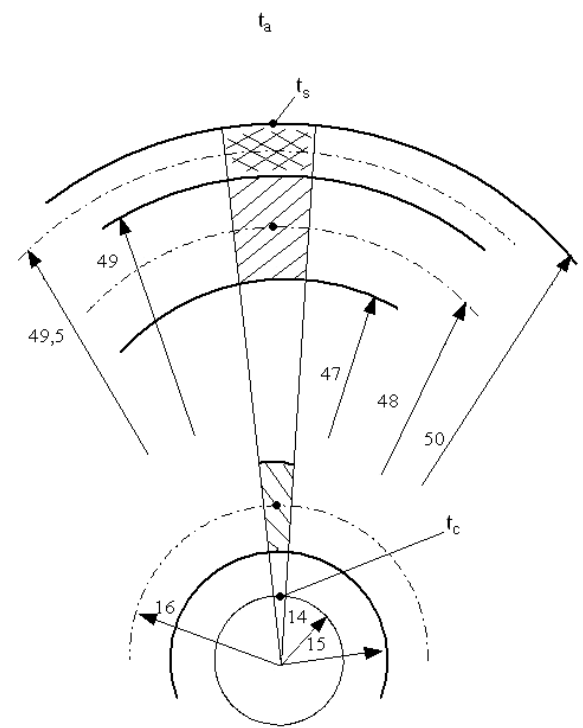

Fig.4 The control volume net

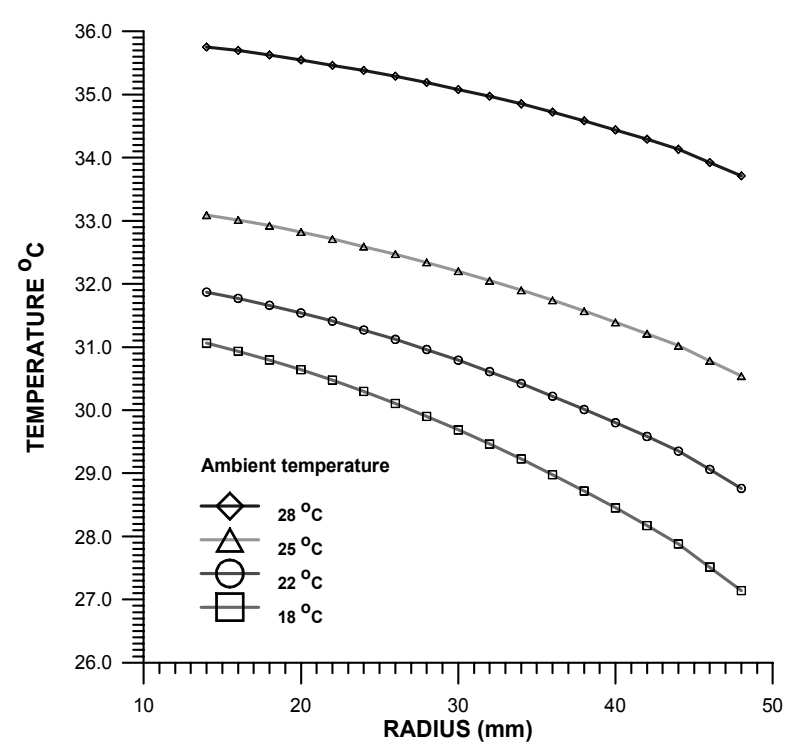

Fig 5 Temperature distribution through tissue for different ambient temperature 